Meta Lah

\title{
Medkulturno skozi čas: medkulturne vsebine $v$ učbenikih francoščine kot tujega jezika
}

Ključne besede: pouk tujih jezikov, (med)kulturna kompetenca, učbeniki za tuje jezike

\section{$1 \quad$ Uvod}

Pouk tujega jezika si zelo težko predstavljamo brez medkulturnih vsebin. Učenca namreč želimo pripraviti na učinkovito komunikacijo v ciljnem jeziku; ta pa ne more zaobjemati le pravilno rabljenih jezikovnih struktur, besedišča in drugih jezikovnih sestavin, temveč tudi ustrezno védenje o kulturi dežele, ki mu bo omogočilo učinkovito in čim manj boleče vključevanje v pogovor s tujci, morda tudi bivanje v ciljni deželi.

Po poskusu definicije kulture se bomo v članku posvetili analizi učbenikov za francoščino kot tuji jezik, ki so se oziroma se še uporabljajo v slovenskem prostoru. Pregledali bomo vsebine, ki se nanašajo na kulturo Francije in drugih frankofonih dežel. Analizirali bomo zadnja dva slovenska učbenika, Južničevega in Gradovega, ter več francoskih učbenikov, ki so namenjeni svetovnemu tržišču. Skušali bomo definirati medkulturne vsebine, opraviti pregled učbenikov, ki pripadajo različnim metodologijam učenja/poučevanja tujega jezika, ter hkrati s tem ugotoviti, kako se je podajanje medkulturnih vsebin spreminjalo skozi čas.

V slovenskem prostoru za »medkulturno« zasledimo tako izraz »interkulturno« (npr. Javornik Krečič, Lebar, 2010) kot »medkulturno« (npr. Medkulturne razsežnosti tujejezikovnega pouka, poglavje $\mathrm{v}$ zborniku Učenje in poučevanje tujih jezikov na Slovenskem). Zdi se, da je izraz "medkulturno« na področju tujejezikovne didaktike bolj uveljavljen, zato ga bomo uporabljali tudi v tem prispevku.

$\mathrm{O}$ medkulturnem lahko $\mathrm{v}$ slovenskem prostoru govorimo $\mathrm{v}$ dveh različnih kontekstih. Pri prvem gre za položaj otrok, ki so vključeni v naše jezikovno okolje, ciljni jezik je torej slovenščina, kulturne kompetence pa tiste, ki pritičejo našemu jeziku. Javornik Krečič in Lebarjeva $(2010,80)$ ugotavljata, da »slovenska šola predstavlja mešanico različnih kultur, njena socialno-kulturna pestrost pa se je $z$ vstopom v Evropsko unijo še povečala«. Podobno ugotovitev zasledimo pri Fidlerjevi 
(2008, 423): „Ob teoretično lepi ponudbi drugega tujega jezika pa se nehote pozablja na zelo pomemben vidik novejše stvarnosti v naših razredih, namreč, da je vedno več učencev iz drugih jezikovnih in kulturnih okolij.« Gre torej za vključevanje skupine (v raziskavi Javornik Krečičeve in Lebarjeve gre za skupino romskih otrok v Pomurju) ali posameznikov, izhajajočih iz drugih kulturnih okolij, v slovensko družbo.

Drugi kontekst je veliko bolj pogost: gre za učence tujega jezika, ki se tega jezika učijo v Sloveniji, in sicer s pomočjo (večinoma) slovenskih učiteljev, pri čemer je ciljna dežela zanje veliko bolj oddaljena kot ciljna dežela otrok v prvem primeru. Konteksta se močno razlikujeta tako po vnosu različnih stimulusov kot po motivaciji. V pričujočem prispevku nas zanima položaj slovenskih govorcev tujega jezika.

Opozoriti moramo še na razlikovanje med poučevanjem materinščine in tujega jezika. ${ }^{1}$ Pri poučevanju maternega jezika gre za pridobivanje kulturne zmožnosti, ki hkrati izgrajuje identiteto posameznika. Pri učenju tujega jezika posameznik pridobi, kot pravita Cuq in Gruca $(2002,84)$, nekakšen kulturni dodatek, ${ }^{2}$ ki se od materinščine loči po tem, da si ga je posameznik izbral sam. Dodajata še, da je kulturni kapital, kot ga imenuje Bourdieu, drugačen, saj pri učenju tujega jezika ne gre za to, da bi se posameznik popolnoma vključil v skupino s takšnimi ali drugačnimi vrednotami, marveč za to, da do dovolj velike mere obvlada simbolno mrežo, ki v tujem jeziku izgrajuje kulturo, da je sposoben $v$ tem jeziku dojemati smisel in se tudi smiselno izražati. Francoščina kot jezik in kultura, ki jo ta jezik prenaša, bo za Francoza, valonskega Belgijca ali prebivalca Québeca konstitutivni element njegove identitete. Za prebivalca Senegala, kjer je francoščina uradni jezik, bo francoščina neobhoden zidak pri izgradnji njegove identitete; medtem ko je za Italijana francoščina izbrani kulturni dodatek in se bo, s sopostavljanjem obeh kultur, morda lažje zavedel svoje, italijanske identitete.

Na koncu uvodnega poglavja naj še dodamo, da prispevek nima ambicije ukvarjati se z medkulturnim s sociološkega vidika; vsi uporabljeni viri so s področja tujejezikovne didaktike, sociologe navajamo le v primeru, da so jih omenjali glotodidaktični viri.

\section{Poskus definicije medkulturnega}

Da bi se lahko lotili analize medkulturnih vsebin v učbenikih, moramo izraz "(med)kulturno« najprej definirati, kar je vsekakor težka naloga. Kljub temu, da je didaktika tujih jezikov razmeroma mlada veda, se je z opredelitvijo »kulturnega « pri

1 V francoskem prostoru je položaj še nekoliko bolj zapleten, saj se francoščino poučuje kot materni, drugi (zlasti v nekaterih afriških državah, kjer je francoščina uradni jezik in jezik šolanja) in tuji jezik. 
pouku tujih jezikov ukvarjalo precej avtorjev. Koncept je bil, kot pravita Cuq in Gruca (2002, 83), prenesen iz drugih disciplin in žal nikoli zares didaktiziran. Po njunem mnenju bi bilo idealno imeti na razpolago opis francoskih ali frankofonih kulturnih konceptov, kot imamo na razpolago seznam jezikovnih struktur; nekakšno slovnico kulture (Cuq, Gruca, 2002, 86). Sprašujemo se, ali bi bilo to ob hitrem spreminjanju konceptov na tem področju smiselno in sploh mogoče.

Večina avtorjev razlikuje med dvema vrstama »kulture«, visoko kulturo ${ }^{3}$ oziroma Kulturo ( $\mathrm{z}$ veliko začetnico) in antropološko ${ }^{4}$ kulturo oziroma kulturo (z malo začetnico):

Kultura je seveda literatura, glasba, slikarstvo itn., vse tisto, kar od Bourdieuja dalje imenujemo kultivirana kultura, vanjo pa spadajo tudi načini življenja in obnašanja, ki jih poimenujemo antropološka kultura. Za Louisa Porcherja je kultura skupek skupnih načinov obnašanja, načinov gledanja na stvari, razmišljanja in delovanja, ki sooblikujejo posameznike, so torej del deljene dediščine in tvorijo del njihove identitete (Cuq, Gruca, 2002, 83).

Galisson $(1991,148)$ v enem prvih del, ki jih je posvetil kulturi pri pouku tujega jezika, bolj natančno kulturni zaznamovanosti besed, pravi: »Zame je vsakdanje življenje - ki ga živimo s telesom -, v katerega se vključuje »deljena kultura «, zanimivo prav zato, ker obstaja sloj ljudi, ki nimajo druge kulture kot to. S kakšno pravico bi torej zanemarili tisto, kar je edina kulturna (kolektivna) lastnost teh ljudi? « Galisson v istem delu $(1991,149)$ predlaga preprosto razmejitveno shemo:

\section{KULTURA}

$\begin{array}{cc}\text { KULTURNO } & \text { KULTIVIRANO } \\ \text { (deljena kultura) } & \text { (visoka kultura) }\end{array}$

Dejstvo je, da je precej lažje zaznati oziroma zasledovati tako imenovano visoko kulturo. Po konceptu kulture kot ledene gore Fennesa in Hapgoodove (naveden v Mikeln, 2008, 455 in 462) se zavedamo le osmine ali celo devetine tistega, kar je kulturno pogojeno; v vidnem delu ledene gore so navedene lepe umetnosti, književnost, klasična glasba, drama, pesništvo, ljudski plesi, igre in kuhanje - po Galissonu torej večinoma »kultivirano«. V potopljenem delu se znajde vse ostalo, večinoma tisto, kar pripada »deljeni« oziroma antropološki kulturi, med drugim tudi definicije barve kože, koncept pravice, načela vzgoje otrok, odnos do živali, status glede na starost, spol, družbeni razred, poklic itn.

3 V citiranih virih zasledimo izraza »culture cultivée« in »culture savante«; kultivirana in znanstvena kultura.

Culture anthropologique, pri Galissonu tudi »culture partagée«, deljena kultura. 
Po Aline Gohard Radenkovic (citirana v Cuq, Gruca, 2002, 87), so glavne razlike med antropološko in visoko kulturo naslednje:

Antropološka kultura

- je transverzalna in pripada večjemu številu članov določene skupine,

- je implicitna, torej pridobljena na nezaveden in nehoten način,

- ne razlikuje med člani določene skupine.

Kultivirana oziroma visoka kultura pa

- je elitistična, pripada torej manjši skupini ljudi, ki zagotavljajo njeno legitimnost,

- je implicitna in kodirana; prenaša se znotraj skupine in se pridobiva zavestno, na primer s šolanjem ali z obiskovanjem kulturnih prireditev,

- med seboj razlikuje člane določene skupine.

Gohard Radenkoviceva (Cuq, Gruca, 2002, 88) našteva nekaj področij antropološke kulture, ki bi jih lahko imeli za univerzalna; npr. kategorije, vezane na čas, prostor, telo, družbene odnose, smrt, hrano itn.

Čeprav nekateri sodobnejši avtorji menijo, da je kultura pluralna in gre za koherenten sistem odnosov, ki se ga ne da poenostavljati z naštevanjem (npr. Kramsch in drugi, 2008, 15), bomo za analizo vsebin v učbenikih ohranili dve kategoriji:

- vsebine, povezane $\mathrm{z}$ »visoko« kulturo oziroma s Kulturo z veliko začetnico: $\mathrm{v}$ učbenikih zlasti odlomki iz književnih del,

- vsebine, povezane $\mathrm{z}$ »vsakdanjo « kulturo oziroma s kulturo z malo začetnico: $\mathrm{v}$ učbenikih pričakujemo zlasti opise dežel, mest in navad prebivalcev.

Razčistiti moramo še razlikovanje med kulturnim in medkulturnim. Skupni evropski jezikovni okvir $(2011,127)$ »medkulturno« definira takole:

znanje, zavedanje in razumevanje odnosa (podobnosti in različne oblike) med »izvornim okoljem « in »okoljem ciljne skupnosti« ustvarjajo medkulturno ozaveščenost. Treba pa je poudariti, da medkulturna ozaveščenost obsega tudi zavedanje regionalnih in družbenih raznolikosti v obeh svetovih. Bogati ga tudi zavedanje, da obstaja širši nabor kultur, kot so kulture učenčevega J1 in J2. Širše zavedanje pomaga umestiti oba jezika v kontekst. Poleg objektivnega znanja medkulturna ozaveščenost pokriva tudi zavedanje podobe določene skupnosti v očeh druge skupnosti, na katero pogosto vplivajo narodnostni stereotipi.

Gre torej za to, da sta v odnosu obe strani, uporabnikova in ciljna. V učbenikih tujega jezika uporabnikove strani v večini primerov ni mogoče zaznati; avtorji se 
osredotočajo le na kulturo ciljnega jezika ter ne spodbujajo primerjav in razmisleka o obeh kulturah; zato smo predpono »med « v izrazu »medkulturno« dostikrat postavili v oklepaj.

\section{Medkulturno - nasploh, v učbenikih in Skupnem evropskem jezikovnem okviru}

Kot ugotavljata Kern in Liddicoat $(2008,33)$, učenje jezika ni nujno medkulturno učenje. Obstajajo dežele, v katerih ni zaželeno omenjati zahodnjaške kulture, saj se ta preveč razlikuje od domače. Beacco (2000, 37-38) opisuje takšno obliko poučevanja/ učenja francoščine, ki jo poimenuje »dekontekstualizirana«. V njegovem primeru gre za učbenik Tiên Pháp, ki so ga za začetno poučevanje jezika pripravili v Demokratični republiki Vietnam. Osebe, ki nastopajo v učbeniku, niso postavljene v okolje ciljne dežele (urbano okolje, zahodnjaško opremljena stanovanja, navade), temveč so večinoma predstavljene $\mathrm{v}$ lokalnem okolju (v okolju uporabnika učbenika), kjer nastopajo kot tujci. Beacco dodaja, da "za tako odločitvijo brez dvoma stoji namen preprečiti vsak stik s kulturo, katere jezik se zdi kljub temu smiselno poučevati. [...]« Gre tudi za »voljo poskrbeti, da ne pride do akulturacije, in zaščititi tiste (zlasti mlade), ki se sami ne morejo«. Tako gledanje je danes večini evropskih učiteljev tujih jezikov tuje, tudi nam pa se še pred nekaj desetletji ni zdelo tako nenavadno; kot bomo videli iz analiz slovenskih učbenikov, v njih ni bilo prav veliko kulturnih elementov, povezanih s kulturo ciljne dežele. Prav tako tako gledanje ni tuje učiteljem dežel, katerih kultura se bistveno razlikuje od zahodne in zaradi svojih norm univerzalističnih učbenikov ne morejo uporabljati.

Mnenje, ki danes prevladuje v evropskem prostoru, je, da »vsakdo živi svojo lastno kulturo, vendar se lahko izraža ne le prek enega jezika in ene kulture, temveč prek več jezikov in več kultur (Abdallah Pretceille, 1999, 39). Elementi, ki jih pridobimo z učenjem tujega jezika in kulture, bi lahko torej bili dodatek naši; če nekoliko karikiramo, lahko kot primer navedemo slovenske frankofile, ki pri francoskem trgovcu na Rudniku kupujejo francoske proizvode, ki so se jih navadili uporabljati, morda tudi po zaslugi učbenika francoščine.

Kot opozarja večina avtorjev didaktične literature s področja poučevanja tujih jezikov, se je, kar zadeva kulturne vsebine, preobrat v francoskem prostoru zgodil konec petdesetih let prejšnjega stoletja. Pred tem sta se pojma »kultura« in »civilizacija « prekrivala, dostikrat $\mathrm{z}$ idejo superiornosti francoske kulture, ki je bila "predstavljena z veličastnimi spomeniki, od katerih so se nekateri spremenili v stereotipe, ki še vztrajajo« (De Carlo, 1998, 25). Avtorji učbenikov so kulturne vsebine uvajali šele v višje stopnje poučevanja; kot ugotavlja Tagliante $(2006,165)$, 
z eksplicitnim namenom, da bi učencem podali informacije in znanja o ciljni deželi, brez kakršnekoli primerjalne perspektive: šlo je za zgodovino dežele in njenih idej, zgodovino institucij, kulturno in umetnostno zgodovino, predstavitev najpomembnejših spomenikov. Menili so, da je treba najprej znati pravilno govoriti in pisati, preden se lotimo »civilizacije«.

Kar zadeva medkulturno, je bil v evropskem merilu velik preboj storjen s Skupnim evropskim jezikovnim okvirom iz leta $2001 .{ }^{5}$ Avtorji namreč medkulturno ozaveščenost navajajo med učenčevimi/uporabnikovimi zmožnostmi, med medkulturne spretnosti in operativno znanje pa prištevajo:

- sposobnost vzpostavljanja odnosa med izvorno in tujo kulturo;

- kulturno občutljivost in sposobnost identifikacije in uporabe različnih strategij

za navezovanje stikov z ljudmi iz drugih kultur;

- sposobnost izpolnjevanja vloge kulturnega posrednika med lastno in tujo

kulturo in sposobnost učinkovitega reševanja medkulturnih nesporazumov in konfliktov;

- sposobnost preseganja stereotipnih odnosov $(2011,128)$.

Na temo medkulturnega lahko zasledimo veliko raziskav, ${ }^{6}$ nismo pa zasledili raziskav o vplivu učbenikov na percepcijo (med)kulturnega. Učbeniki so omenjeni le v japonski raziskavi M. Himeta. Himeta (2008, 233-237) pravi, da morajo »učitelji v razredu dostikrat popravljati stereotipe o deželi, v kateri se govori tuji jezik, in njenih prebivalcih «, in opozarja na dejstvo, da učitelj »zahvaljujoč osebnim izkušnjam in položaju med dvema kulturama konceptualizira razdaljo, ki je učenci ne poznajo. [...] Predloge, ${ }^{7} \mathrm{ki}$ jih učitelj izbere in predstavi v razredu, imajo na učence velik vpliv. « Himeta v istem članku poroča o rezultatih raziskave, ki jo je izvedla $z$ japonskimi študenti; $v$ raziskavi je merila vpliv različnih dejavnikov na predstave študentov; upoštevala je vpliv pripovedi učitelja, videoposnetkov, učbenika, televizije, kina, tiska, družine in potovanj. Daleč največjo vlogo je na učence imela televizija, takoj za njo pa pripovedi učitelja. Učbenik je pri japonskih učencih igral bistveno manjšo vlogo, kljub temu pa večjo od tiska in potovanj. Podobno raziskavo bi bilo zanimivo ponoviti v evropskem okolju, kjer so razdalje manjše in je kulturni vpliv verjetno večji kot na Japonskem. Vključitev učbenikov v raziskavo potrjuje dejstvo, da je tudi učbenik eden od dejavnikov, ki pomembno vplivajo na predstave o tuji deželi.

$5 \quad$ V Sloveniji preveden 2011.

6 Ena trenutno poteka tudi pri nas; $\mathrm{v}$ okviru doktorskega študija jo izvaja Saška Horvat.

7 Med predloge bi lahko šteli tudi učbenike, saj jih v večini primerov izbere učitelj. 


\section{$4 \quad$ Analiza (med)kulturnih vsebin v nekaterih učbenikih francoščine kot tujega jezika}

Za analizo (med)kulturnih vsebin smo izbrali pet učbenikov:

- Francosko vadnico Rudolfa Južniča, leto izdaje 1938,

- Francosko vadnico Antona Grada, leto izdaje 1954,

- Cours de langue et de civilisation françaises G. Maugera (v didaktični literaturi poimenovan »Mauger bleu«), leto izdaje 1953,

- Le nouveau sans frontières, več avtorjev (gl. seznam literature), leto izdaje 1988 ,

- Nouveau rond point, več avtorjev (gl. seznam literature), leto izdaje 2011.

Prva dva učbenika sta zadnja učbenika slovenskih avtorjev. Za Gradovimi učbeniki se $\mathrm{v}$ slovenskem šolskem prostoru niso več uporabljali slovenski učbeniki, marveč povečini prirejeni hrvaški, na primer Parlons et lisons (Batušić, Montani) in Réfléchis et dis-le en français (Batušić, Vrhovac). Učbeniki so bili deloma prirejeni za slovensko tržišče; prevedeno je bilo na primer besedišče in razlage slovnice. Za obravnavo (med) kulturnih vsebin bi bili brez dvoma zanimivejši povsem slovenski učbeniki, žal pa se po že omenjenih priredbah hrvaških učbenikov v slovenskem prostoru uporabljajo francoski ${ }^{8}$ učbeniki, namenjeni svetovnemu trgu, ki ne upoštevajo jezikovnih in kulturnih specifik slovenske publike. ${ }^{9}$

Obravnavani učbeniki sledijo različnim metodologijam:

- slovenska učbenika tradicionalni, ${ }^{10}$ slovnično-prevajalni metodi poučevanja tujega jezika,

- Mauger bleu direktni metodi,

- Le nouveau sans frontières komunikacijskemu pristopu,

- Nouveau rond point akcijskemu pristopu.

Zaradi primerljivosti smo pri vseh učbenikih analizirali le učbenik (ki ga ima na razpolago učenec) in le prvo stopnjo.

Pred analizo (med)kulturnih vsebin v omenjenih učbenikih sta naši izhodiščni hipotezi dve. Pričakujemo, da bo v starejših učbenikih več kulturnih vsebin s področja "visoke« kulture, na primer več odlomkov književnih del, v novejših pa več vsakdanjih vsebin, povezanih z običaji in navadami ciljne dežele. Naša druga predpostavka je

8 Ali francosko-španski, na primer Rond point, Nouveau rond point in Version originale.

9 Rond point je bil sicer prirejen za slovenske učence, vendar je šlo zgolj za prevode slovničnih razlag in besedišča; sprašujemo se, ali je bilo to sploh smiselno.

10 V francoščini: »méthode traditionnelle«. 
vezana na razlikovanje med kulturnim in medkulturnim. Pričakujemo, da bo glede na smernice sodobnega jezikovnega pouka, npr. tiste Skupnega evropskega jezikovnega okvira, zlasti v najnovejšem učbeniku več medkulturnih vsebin, se pravi več tistih vsebin, pri katerih bo učenec napeljan $\mathrm{k}$ primerjavi tuje in lastne kulture in bo $\mathrm{s}$ pomočjo tuje uzaveščal lastno.

\subsection{Rudolf Južnič: Francoska vadnica}

$\mathrm{V}$ vadnici večinoma ni mogoče zaznati (med)kulturnih vsebin. V posameznih enotah je Francija omenjena le enkrat, in sicer v besedilu La Yougoslavie et la France (str. 42), kjer avtor v 6 vrsticah opiše obe državi, imenuje glavni mesti in hkrati doda, da je »Francija evropska država. Ta dežela je lepa in bogata. Tudi njeno glavno mesto je lepo.«

$\mathrm{V}$ dodatku, na straneh 80 in 81 , najdemo tri kratke anekdote, eno pesem (Chez l'épicier) in ljudsko pesem Au clair de la lune. Vsa navedena besedila so uporabljena brez navedbe vira.

V vseh primerih gre za besedila, ki bi jih lahko uvrstili v »vsakdanjo« kulturo.

\subsection{Anton Grad: Francoska vadnica}

Gradova vadnica se po količini uporabljenih (med)kulturnih vsebin ne razlikuje dosti od Južničeve. Zanimivo je, da je v redkih primerih, ko so te vsebine sploh omenjene, večkrat omenjena Jugoslavija kot Francija. Na str. 20 je npr. opisana jugoslovanska zastava (na kratko primerjana s francosko), na str. 39 pa je med predmeti v razredu omenjen portret maršala Tita. Tako Južnič kot Grad sta kot izhodiščni kontekst uporabila kontekst učenca, se pravi takratno jugoslovansko okolje. Taka izbira je bila gotovo pogojena z družbenimi razmerami, pa tudi s tem, da so bili stiki s ciljno državo veliko bolj omejeni kot v kasnejših letih.

\subsection{Mauger: Cours de langue et de civilisation françaises}

Čeprav je učbenik izšel leto dni pred Gradovo vadnico, je, kar se kulturnih vsebin tiče, njegova naravnanost povsem drugačna, kar nakazuje že naslov učbenika. Avtor izhaja iz predpostavke, da sta francoska civilizacija in kultura bogati; njegova namera je širiti to kulturo po vsem svetu, saj je učbenik namenjen "učencem vseh držav«. Francoska superiornost se kaže že v uvodu, ki ga je napisal generalni sekretar Alliance Française. Med drugim pravi tudi: 
Na Alliance Française menimo, da vemo, zakaj se prebivalci Skupnosti in tuje elite učijo francosko. Ne gre za to, da bi med sabo lahko stkali osnovne stike. Prav tako ne gre za to, da bi bila njihova potovanja bolj udobna [...]. Gre v prvi vrsti za to, da navežejo stik z eno najbogatejših svetovnih civilizacij, obogatijo svoj duh s študijem čudovite literature in zares postanejo omikani ljudje. [...] Francoščina povzdigne, hkrati pa je tudi uporabna ${ }^{11}$ (Mauger bleu, VI).

Kulturno in civilizacijsko naravnanost učbenika potrdi tudi avtor sam, ki v uvodu zapiše:

[...] ne gre samo za učbenik jezika, pač pa tudi - in od prvega dela učbenika dalje - za učbenik francoske civilizacije. S pomočjo izmišljene tuje družine na obisku v Franciji bo imel učenec pred očmi zvest portret navad naše dežele; lahko se bo poistovetil z junaki in se počutil, kot bi v njihovi družbi obiskal Francijo. [...] Dana je torej priložnost primerjati francoski način življenja z navadami drugih ljudstev (Mauger bleu, VIII).

$\mathrm{V}$ učbeniku najdemo veliko elementov, povezanih $\mathrm{s}$ francosko kulturo in civilizacijo, pa tudi elementov kanadske kulture, med drugim:

- fotografije francoskih mest in znamenitosti (Pariz, Le Havre, Lourdes, Reims, Pireneji),

- fotografije in risbe znamenitosti Pariza,

- fotografije dokumentov, npr. potnega lista (str. 62) in vozovnice (str. 79),

- zemljevide Pariza, Francije in Kanade.

V zadnjem delu učbenika je dodatek, poimenovan En France, v Franciji. Zavzema 22 strani in je razdeljen na tri dele: Dokumenti, Pesmi in Poezije.

V Dokumentih so kratka besedila, opremljena s fotografijami. Gre za informacije, povezane z vsakdanjim življenjem v Franciji, napaberkovane na videz brez vsakega reda. Tako najdemo, na primer, izraze za pozdrave (str. 188), informacije o različnih tipih stanovanj (str. 190), opise kulinaričnih posebnosti (»Francozi pogosto jedo polže na začetku obroka. Pripravijo jih $\mathrm{z}$ maslom in česnom ter jih zapečejo v pečici. Francozi imajo zelo radi tudi školjke. Njihova strast do žab pa je legendarna.«, str. 192), informacije o metroju (str. 194), drugih načinih prevoza (str. 195) in Baskih (»Baski so zelo stara rasa. Govorijo jezik, katerega slovnica ni podobna nobeni drugi.«, str. 198). V vseh navedenih primerih gre za opise, večinoma navad in običajev, torej za »vsakdanjo« kulturo.

$\mathrm{V}$ razdelku Pesmi najdemo tri ljudske pesmi z notami. Gre za splošno znane pesmi, del folklore, ki jih pozna večina prebivalcev Francije (oziroma jih je verjetno poznala v tistem času), torej prav tako za »vsakdanjo« kulturo.

11 »Le français élève, et, en même temps, il sert.« 
Del Poezije prinaša 13 pesmi francoskih in enega belgijskega pesnika, od J. Préverta do V. Hugoja in G. de Nervala, predstavljeni so tudi nekateri manj znani avtorji. Ta del lahko uvrstimo v »visoko« kulturo.

(Med)kulturnih elementov kljub napovedi v uvodu (gl. zgoraj) v učbeniku ni mogoče zaznati.

\subsection{Le nouveau sans frontières}

Od vseh pregledanih učbenikov (med)kulturne vsebine najtežje zaznamo in opišemo prav v tem učbeniku. Zelo verjetno gre za posledico dejstva, da je učbenik eden prvih, ki je bil v francoskem prostoru zasnovan po komunikacijski metodi. Avtorji so $\mathrm{v}$ želji po čim večji avtentičnosti pouka uporabili veliko izvirnega gradiva, zlasti fotografij; te fotografije pa dostikrat posegajo na področje francoske kulture. Žal so predloge uporabljene stihijsko, brez pravega načrta, zato jih je težko kategorizirati. V učbeniku najdemo, na primer: fotografije znanih francoskih osebnosti (skoraj v vsaki enoti), fotografije krajev in znamenitosti (npr. na str. 13, 37, 52-53), reprodukcije slik (npr. Moneta in Picassa, str. 29, ter Van Gogha, str. 116-117), opise francoskih pokrajin (str. 100-101, 185), predstavitev zgodovinskih osebnosti (str. 141), osebnosti iz stripov (str. 147), naslovnice časopisov (str. 181) in opis francoskih praznikov (str. 93).

Vse zaznane kulturne vsebine v učbeniku uvrščamo v »vsakdanjo« kulturo. Nekaj dvomov imamo pri reprodukcijah del slikarjev, vendar gre za tako znane avtorje in dela, da najbrž tudi te reprodukcije pozna večina Francozov in njihovo poznavanje med prebivalci Francije ne razlikuje.

(Med)kulturnih elementov v učbeniku ni mogoče zaznati.

\subsection{Nouveau rond point}

Učbenik je prvi od analiziranih, ki ima medkulturnim vsebinam posvečen razdelek v vsaki enoti, kar označuje že naslov tega razdelka, Regards croisés, Prekrižani pogledi. Medkulturne vsebine so napovedane in jasno razdelane tudi v kazalu.

Teme, povezane s francosko in frankofono kulturo, najdemo razpršene preko celotnih enot in jih je težko oddvojiti od ostalih. Dostikrat so te vsebine predstavljene kot izhodišče za opravila oziroma naloge, ki jih mora učenec (ali skupina učencev) izpeljati.

Kar ta učbenik razlikuje od prejšnjih, je, da je edini vsaj do neke mere zasnovan medkulturno. 
Naloga C razdelka Regards croisés namreč vsakokrat poseže na področje kulture uporabnika učbenika in ga pripravi do tega, da primerja predstavljeno z lastnimi izkušnjami. V tretji enoti (str. 38-39) so predstavljeni regionalni jeziki, ki se govorijo v Franciji, in jezikovna situacija v Belgiji, Kanadi in Švici. Naloga C se glasi: »Kateri so jeziki, ki se govorijo v vaši deželi ali v vaši pokrajini? Kaj pa v vaši družini? «. V peti enoti so predstavljeni nekateri manj znani francoski prazniki, naloga C pa je: »Ali ti prazniki obstajajo tudi pri vas? So znani?«.

Čeprav so vprašanja večinoma zelo osnovna in jezikovno znanje uporabnikov učbenika na tej stopnji še ni dovolj veliko, da bi nanje lahko argumentirano odgovorili, je treba avtorjem učbenika priznati, da so o medkulturnem razmišljali in ga v učbenik poskusili vključiti.

Vse (med)kulturne vsebine, predstavljene v učbeniku, lahko uvrstimo na področje »vsakdanje« kulture.

\subsection{Sinteza}

Po pregledu omenjenih petih učbenikov ugotavljamo, da v obeh slovenskih učbenikih (med)kulturnih vsebin praktično ni. Redki elementi, ki jih lahko opazimo, posegajo na področje vsakdanje kulture in so umeščeni $\mathrm{v}$ kontekst učenca, ne $\mathrm{v}$ kontekst kulture ciljnega jezika.

Vsi trije francoski učbeniki vsebujejo kulturne elemente, prva dva le kulturne, saj na področje medkulturnega ne posegata, zadnji pa tudi nekaj nalog, ki služijo medkulturnemu osveščanju učencev. Književna dela (se pravi elemente »visoke« kulture) vsebuje le najstarejši učbenik, ostala dva posegata na področje vsakdanje kulture.

\section{$5 \quad$ Zaključek}

Medkulturne vsebine imajo pri pouku tujega jezika pomembno vlogo. Eden od ciljev tujejezikovnega pouka bi po našem prepričanju moralo biti tudi oblikovanje osebnosti, ki do tuje kulture pristopajo kritično, če je to potrebno, vendar brez predsodkov in vnaprej ustvarjenih mnenj.

$\mathrm{V}$ prispevku smo skušali osvetliti vlogo, ki so jo pri podajanju medkulturnih vsebin skozi čas odigrali učbeniki francoščine. Predstavljene kulturne vsebine smo razdelili na dve področji: področje visoke in področje vsakdanje kulture, pri čemer "visoko« kulturo definiramo kot tisto, ki pripada manjši skupini ljudi in razlikuje med pripadniki določene skupine. Za pregled smo izbrali pet učbenikov, ki so nastali 
na podlagi različnih metodologij in v različnih obdobjih: zadnja dva zares slovenska učbenika (pripadata tradicionalni metodi učenja/poučevanja) in tri francoske učbenike, ki so nastali od petdesetih let prejšnjega stoletja do lani - Mauger bleu (direktna metoda), Le nouveau sans frontières (komunikacijski pristop) in Nouveau rond point (akcijski pristop).

Glede na uporabljene metodologije smo predvidevali, da bo v starejših, zlasti slovenskih učbenikih več kulturnih vsebin s področja »visoke kulture«. Ta predpostavka se ni povsem potrdila. V slovenskih učbenikih kulturnih vsebin praktično ni, res pa je največ vsebin s področja "visoke« kulture v najstarejšem francoskem učbeniku, Cours de langue et de civilisation françaises.

Naša druga predpostavka je posegala na področje medkulturnega. Predpostavljali smo, da bo največ zares medkulturnih vsebin $\mathrm{v}$ najnovejšem učbeniku, ki sledi smernicam Skupnega evropskega okvira. To predpostavko bi lahko potrdili; v starejših učbenikih so kulturne vsebine predstavljene enostransko, brez povezave s kulturo uporabnika učbenika. V Nouveau rond point je ena naloga vsake enote posvečena primerjanju obeh kultur. Čeprav naloge občasno ostajajo na osnovni, rudimentarni ravni, je kljub temu mogoče zaznati preskok v miselnosti avtorjev učbenika, ki so končno začeli upoštevati tudi kulturo tistega, ki bo njihov učbenik uporabljal.

Želimo si, da bi bilo medkulturnih vsebin v učbenikih več in da bi bile predstavljene na nevtralen način, ki ne bi spodbujal nastanka stereotipov. Kar se dojemanja kulture tiče, se lahko le strinjamo z Robertom Galissonom, enim prvih avtorjev, ki je v francoskem prostoru posegel na področje medkulturnega. Že leta 1991 je namreč zapisal:

Svoje kulture ne ponujam v občudovanje. Ne zdi se mi na mestu, da bi poveličeval različnost; vse kulture so različne. Opazim lahko, da moja zbuja zanimanje prav zaradi različnosti. Tujci se z njo ne bi ukvarjali, če bi bila identična njihovi; česar ne najdejo doma, jih privlači pri nas. Moja naloga je prozaično opisati različnosti (kulture), ne poveličevati resnic. Zavedam se, da skozi mojo kulturo ne delujem bolje, pač pa različno od drugih. Na kratko povedano, urim se v nevtralnosti (Galisson, 1991, 150).

\section{Literatura}

Abdallah-Pretceille, M., L'éducation interculturelle, Pariz 2005.

Beacco, J.-Cl., Les dimensions culturelles des enseignements de langue, Pariz 2000.

Chaves, R. M., Favier, L., Pélissier, S., L'interculturel en classe, Grenoble 2012.

Cuq, J.-P., Gruca, I., Cours de didactique du français, langue étrangère et seconde, Grenoble 2002. 
De Carlo, M., L'interculturel, Pariz 1998.

Dictionnaire de didactique du français, langue étrangère et seconde (ur. Cuq, J.-P.), Pariz 2003, str. 136-138.

Fidler, S., Jezikovno in medkulturno uzaveščanje $\mathrm{z}$ večjezičnim pristopom, v: Učenje in poučevanje tujih jezikov na Slovenskem (ur. Skela, J.), Ljubljana 2008, str. 422-439.

Galisson, R., De la langue à la culture par les mots, Pariz 1991.

Himeta, M., Entre distance et proximité: L'évolution de la relation stéréotypée des apprenants avec la culture étrangère, v: Précis du plurilinguisme et $d u$ pluriculturalisme (ur. Zarate, G., in drugi), Pariz 2008, str. 233-237.

Javornik Krečič, M., Lebar, V., Pomembnost interkulturnih svetovalnih kompetenc po mnenju učiteljev v osnovni šoli, Revija za elementarno izobraževanje 3, 2010, str. 79-94.

Kern, R., Liddicoat, A., Introduction: de l'apprenant au locuteur/acteur, v: Précis $d u$ plurilinguisme et du pluriculturalisme (ur. Zarate, G., in drugi), Pariz 2008, str. 27-31.

Kramsch, C., Lévy, D., Zarate, G., Introduction générale, v: Précis du plurilinguisme et du pluriculturalisme (ur. Zarate, G., in drugi), Pariz 2008, str. 15-23.

Mikeln, P., Poenostavljena besedila za otroke in medkulturno ozaveščanje, v: Učenje in poučevanje tujih jezikov na Slovenskem (ur. Skela, J.), Ljubljana 2008, str. 452-464.

Skupni evropski jezikovni okvir, Ministrstvo za šolstvo, Ljubljana 2011.

Šečerov, N., Učiteljeva vloga pri razvijanju medkulturne zmožnosti, v: Učenje in poučevanje tujih jezikov na Slovenskem (ur. Skela, J.), Ljubljana 2008, str. 465-479.

Tagliante, Ch., La classe de langue, Pariz 2006.

\section{Analizirani učbeniki}

Dominique, Ph., Girardet, J., Verdelhan M. in M., Le nouveau sans frontières 1, CLE International, Pariz 1988.

Flumian, C., Labascoule, J., Lause, Ch., Royer, C., Nouveau rond point 1, Éd. Maison de langues, Pariz, Barcelona 2011.

Grad, A., Francoska vadnica, prva stopnja, za 1. razred nižjih gimnazij, DZS, Ljubljana 1954.

Južnič, R., Francoska vadnica, 1. letnik, druga, izpremenjena izdaja, Učiteljska tiskarna v Ljubljani, Ljubljana 1938.

Mauger, G., Cours de langue et de civilisation françaises 1, Hachette, Pariz 1953. 
Meta Lah

\section{The Concept of the Interculture in Time: (Inter)cultural Topics in Textbooks of French as a Foreign Language}

Keywords: Language teaching, (inter)cultural competence, foreign language textbooks

The article deals with the concept of interculturality as used in foreign language didactics. In accordance with the definition of interculturality given in the first part of the article, two categories are included in the analysis - two "levels" of culture, each of them bearing a different name in literature, namely high and popular culture. Various textbooks used for teaching French as a foreign language in Slovenia in both the past and present were chosen for the analysis of topics that cover a fairly long period of time - among them the textbooks by two Slovenian authors: Južnič (1938) and Grad (1954), as well as some generally-used French textbooks, such as Cours de langue et de civilisation françaises (1953), Le nouveau sans frontières (1988) and Nouveau rond point (2011).

The article is based on the hypothesis that high culture is more likely to be present in the older textbooks, which are based on traditional methods, whereas in modern textbooks more popular, everyday topics can be found. It is also presumed that topics in modern textbooks are, compared to their more traditional counterparts, introduced in an intercultural manner which could encourage students to compare the culture of the foreign country with their own.

Both hypotheses are partly confirmed. In Slovenian textbooks there are very few culture-based topics. On the other hand, they are present in all French textbooks, regardless of the methodology. It is true that Mauger introduces more high culture than the others and that the intercultural topics are presented only in the most recent textbook. In all the others, it is exclusively the culture of the target country that is introduced. 